\title{
Experimental Determination of Optimum Exchanged Diameter in Surface Grinding Process
}

\author{
Vu Ngoc $\mathrm{Pi}^{1}$, Luu Anh Tung ${ }^{1}$, Le Xuan Hung ${ }^{1}$ and Nguyen Van Ngoc ${ }^{2}$ \\ 1. Mechanical Engineering Faculty, Thai Nguyen University of Technology, Thai Nguyen 250000, Vietnam \\ 2. Mechanical Engineering Faculty, Ha Tinh Intermediate Vocational School, Ha Tinh 480000, Vietnam
}

\begin{abstract}
This paper presents an experimental study that helps to determine the optimum exchanged diameter in surface grinding. In the paper, the cost of a surface grinding process was analysed. In the cost structure, the effects of the cost parameters such as machine tool hourly rate, grinding wheel cost were taken into account. Also, process parameters including the initial grinding wheel diameter, the wheel life, the dressing regime and so on were investigated. Based on the cost structure, the set up and the procedure of the experiment for finding the optimum diameter was pointed out. From experimental results, the optimum exchanged grinding wheel diameter was found. Grinding with the optimum exchanged diameter, both the grinding cost and grinding time can be reduced significantly.
\end{abstract}

Key words: Grinding, grinding process, surface grinding, experimental study.

\section{Introduction}

Grinding is one of main methods of precision machining which accounts for about $20-25 \%$ of the total expenditures on machining operations in industries [1]. Therefore, optimization of grinding process has been the subject of many studies. Optimum researches of grinding process are usually performed on finding optimum parameters of grinding regimes in different grinding types such as for external cylindrical grinding [2, 3], for surface grinding $[4,5]$ and for internal grinding process [6,7]. Also, there have been some studies of theoretical learning about optimum exchanged grinding wheel diameters in external grinding [8], surface grinding [9] and internal grinding [10]. However, there is still lack of an experimental study on the optimization of grinding process for determination of the optimum exchanged grinding wheel diameter.

This paper introduces an experimental study for finding the optimum exchanged grinding wheel diameter in surface grinding. From the results of the

Corresponding author: $\mathrm{Vu}$ Ngoc Pi, Ph.D., main research fields: abrasive machining and optimum design. study, the optimum diameter was found and grinding with the optimum exchanged diameter, both the grinding time and grinding cost will be reduced considerably.

\section{Theoretical Analysis}

In surface grinding process, the manufacturing single cost per piece $C_{\text {sin }}$ can be determined as Eq. (1):

$$
C_{\mathrm{sin}}=t_{s} \cdot C_{m t, h}+C_{g w, p}
$$

in which,

$C_{m t, h}$-Machine tool hourly rate (USD/h) including wages, overhead, and cost of maintenance etc.;

$C_{g w, p}$-Grinding wheel cost per workpiece (USD/workpiece); $C_{g w, p}$ can be calculated by:

$$
C_{g w, p}=C_{g w} / n_{p, w}
$$

where, $C_{g w}$ is the cost of a surface grinding wheel (USD/piece); $n_{p, w}$ is total number of workpieces ground by a grinding wheel; $n_{p, w}$ can be determined by Eq. (3):

$$
n_{p, w}=n_{p, d} \cdot n_{d}
$$

where $n_{p, d}$ is number of workpieces per dress; $n_{p, d}$ 


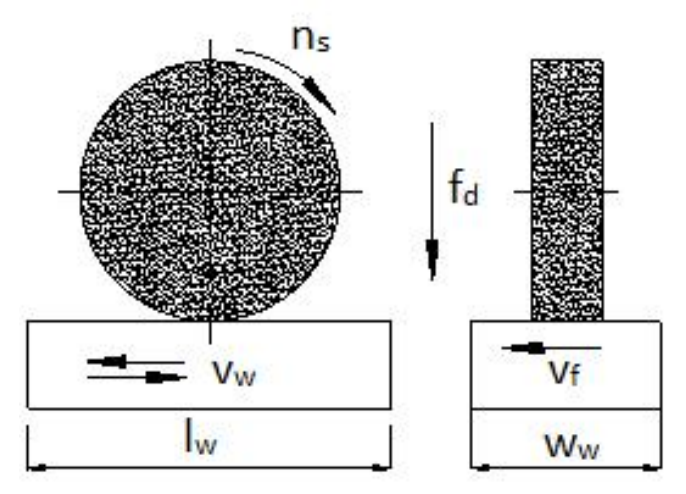

Fig. 1 Schema of surface grinding.

will be determined by experiment; $n_{d}$ is the number of dressing passes; $n_{d}$ is calculated by Rowe, W. B. [11]:

$$
n_{d}=\left(d_{s, 0}-d_{s, e}\right) /\left[2 \cdot\left(\delta_{r s}+a_{e d, g e s}\right)\right]
$$

in which, $d_{s, 0}$ is the initial grinding wheel diameter $(\mathrm{mm}) ; d_{s, e}$ is exchanged grinding wheel diameter $(\mathrm{mm}) ; \delta_{r s}$ is the radial grinding wheel wear per dress $(\mathrm{mm} / \mathrm{dress}) ; a_{e d, g e s}$ is total depth of dressing cut (mm).

$t_{s}$-Manufacturing time includes auxiliary time (h); in surface grinding process, the manufacturing time can be express as Eq. (5):

$$
t_{s}=t_{c}+t_{l u}+t_{s p}+t_{d, p}+t_{c w, p}
$$

where, $t_{c}$ is grinding time (h); $t_{l u}$ time for loading and unloading workpiece (h); $t_{s p}$-spark-out time (h); $t_{d, p}$ is the dressing time per piece (h); $t_{d, p}$ is calculated as Eq. (6):

$$
t_{d, p}=t_{d} / n_{p, d}
$$

With $t_{d}$ is dressing time (h);

$t_{c w, p}$ is time for changing a grinding wheel per workpiece (h); $t_{c w, p}$ can be calculated as Eq. (7):

$$
t_{c w, p}=t_{c w} / n_{p, w}
$$

With $t_{c w}$ is time for changing a grinding wheel (h);

Thus, to calculate the cost of surface grinding process, it is necessary to conduct experiments to determine the parameters mentioned above such as the grinding time, the average wear of abrasive after each dressing, number of workpieces per dress.

\section{Experimental Setup and Procedure}

\subsection{Experimental Setup}

The setup of the experiment was shown in Fig. 2. The grinding parameters are as:

- Grinding machine Moto-Yokohama;

- Force measuring system Kistler 5233A;

- Grinding wheel Cn80MV1 $300 \times 127 \times 30$;

- Multipoint diamond dresser 3908-008C (type 2);

- Workpiece material: 9CrSi;

- Workpiece dimensions $10 \times 60 \times 25\left(\mathrm{~mm}^{3}\right)$;

- Total depth of dressing cut: $0.15(\mathrm{~mm})$ including for medium finish 3 times $0.03(\mathrm{~mm})$; for fine finish 3 times $0.02(\mathrm{~mm})$;

- Grinding regimes (based on [12]): the grinding wheel speed $n_{w}=1,700(\mathrm{rpm})$; the work feed $v_{f}=$ $10(\mathrm{~m} / \mathrm{min})$; the downfeed $f_{d}=0.02(\mathrm{~mm} / \mathrm{pass})$;

- Values of exchanged grinding wheel diameter: $\phi 290, \phi 280, \phi 270, \phi 260, \phi 250, \phi 240$, $\phi 230$ and $\phi 220$.

\subsection{Experimental Procedure}

The experiment was conducted as: Grinding at 8 values of grinding wheel diameters including $\phi 290$, $\phi 280, \phi 270, \phi 260, \phi 250, \phi 240, \phi 230$ and $\phi 220$. Before grinding, dress with the above regime. In order to find the wheel life, with each value of grinding wheel diameter, the grinding time was longer than the wheel life. The wheel life is easily determined by Kistler system. Also, the grinding time, dressing time and the time for loading and unloading workpiece were determined in this experiment.

\section{Results and Discussion}

It was found that the exchanged grinding wheel diameter effected strongly on the results of the grinding process. Fig. 4 presents the relation between the material removal rate and the exchanged diameter. The effects of the exchanged diameter on the wheel life and the grinding time are shown in the Figs. 5 and 6. 


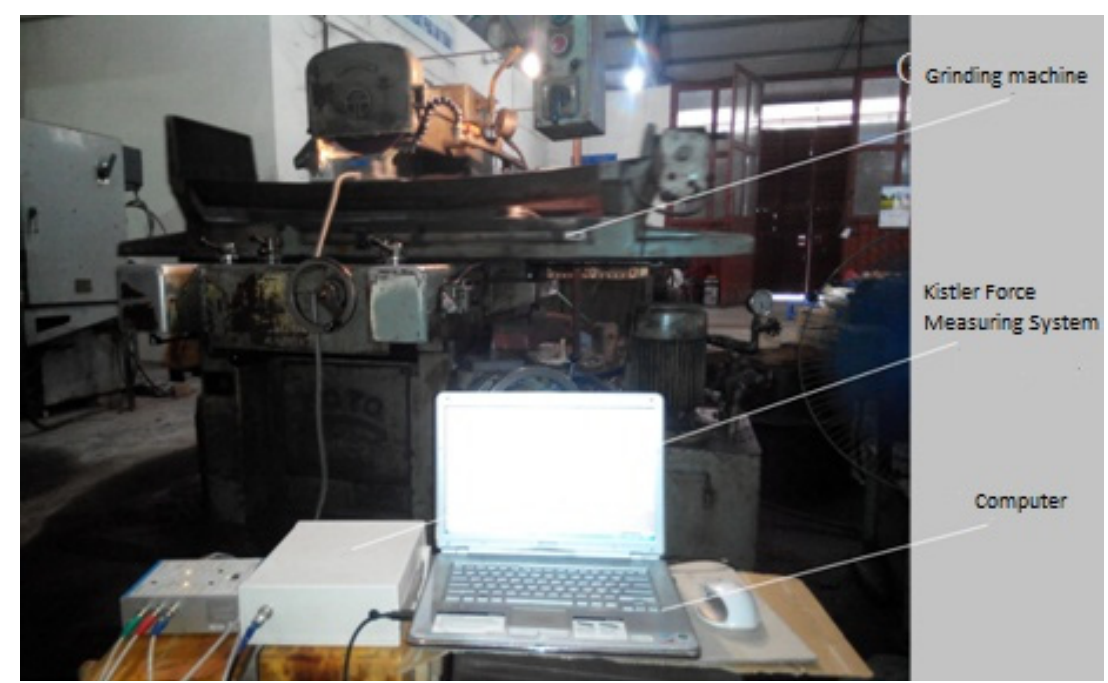

Fig. 2 Photograph of experimental setup.

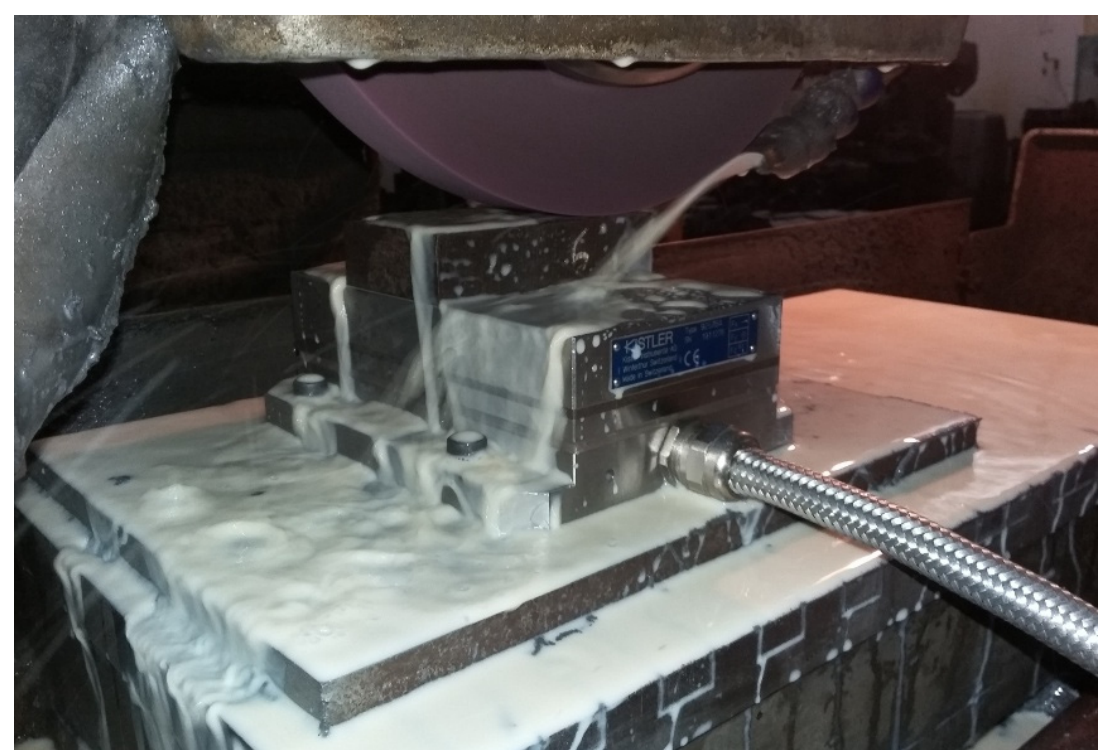

Fig. 3 KISTLER 5233A used in the experiment.

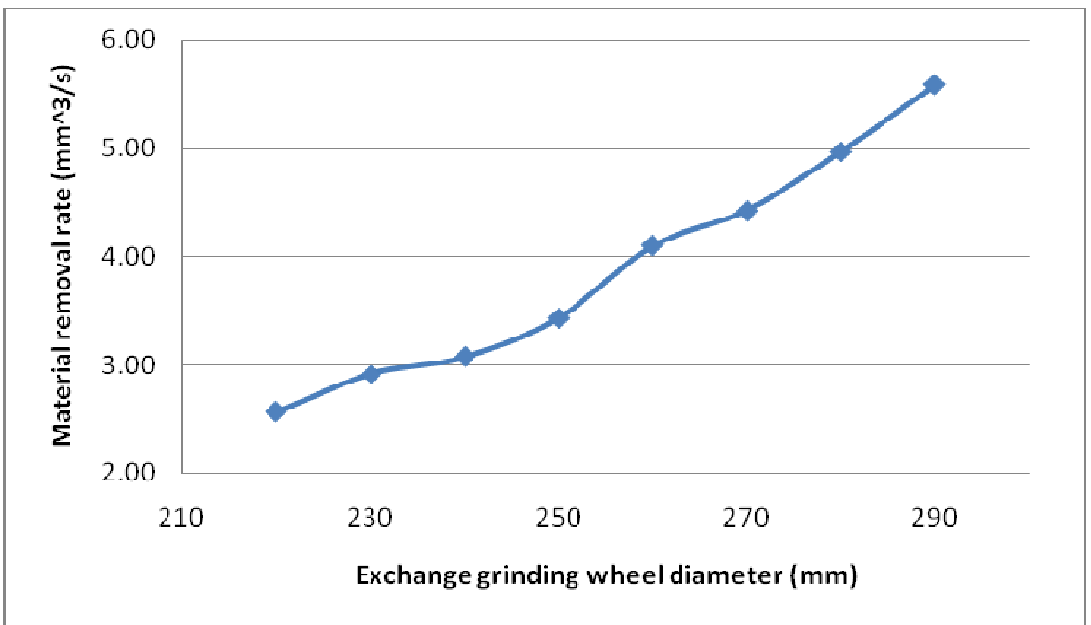

Fig. 4 Material removal rate versus exchanged grinding wheel diameter. 


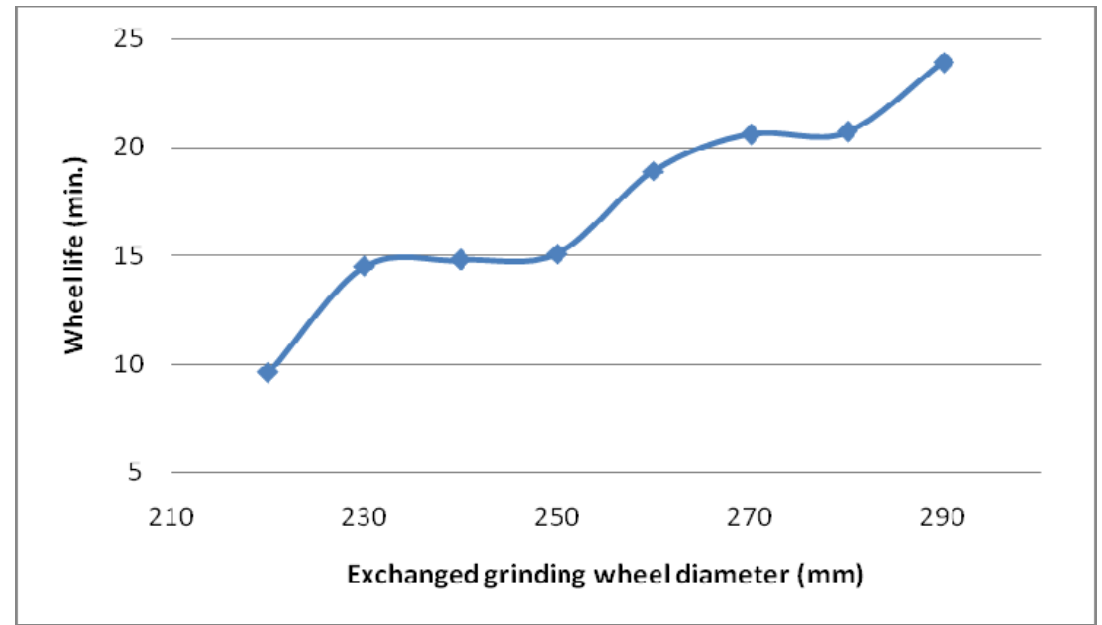

Fig. 5 Wheel life versus exchanged grinding wheel diameter.

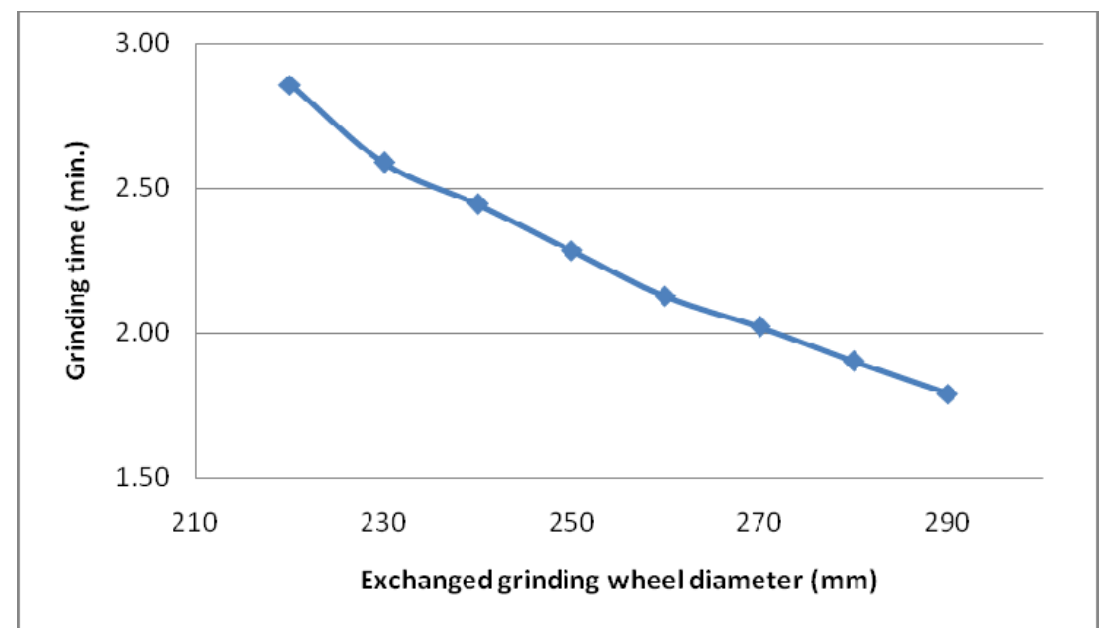

Fig. 6 Grinding time versus exchanged grinding wheel diameter.

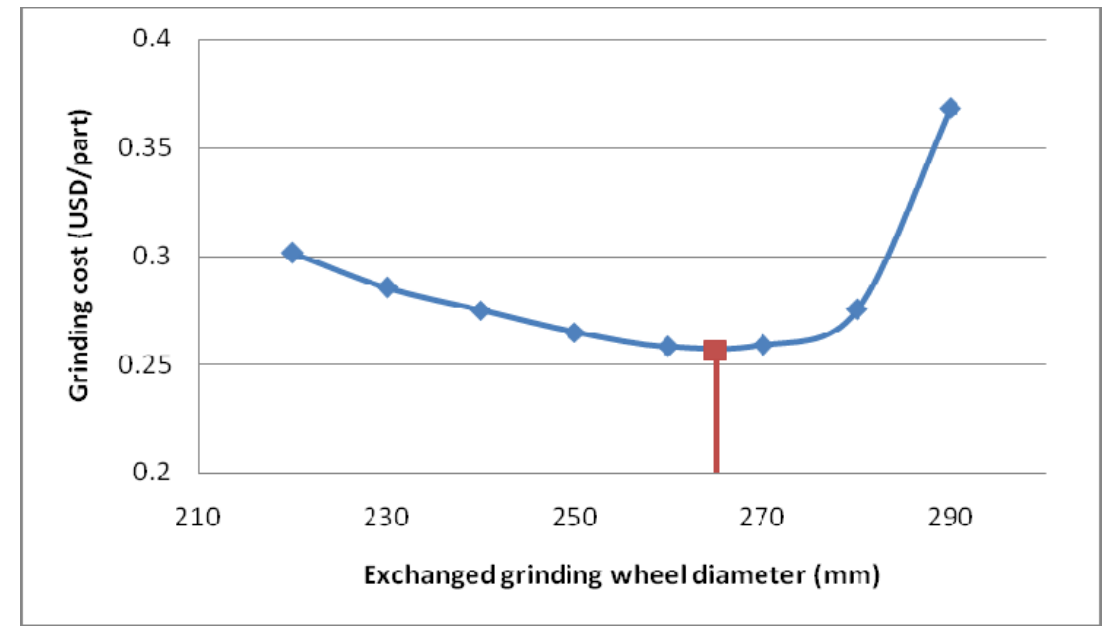

Fig. 7 Grinding cost versus exchanged grinding wheel diameter.

The relation between the exchanged diameter and the grinding cost per part was shown in Fig. 7. It was detected that the grinding cost powerfully depends on the exchanged grinding wheel diameter. Also, there is an optimum value of the exchanged diameter at which the cost gets minimum (Fig. 7). It is interesting that the 
optimum diameter was much larger than the traditional exchanged diameter. In this work, the optimum diameter was about $265 \mathrm{~mm}$ (Fig. 7) while the traditional exchanged diameter was $220 \mathrm{~mm}$. Also, with the optimum diameter the grinding cost per piece was 0.26 (USD/p.) when it was 0.3 (USD/p.) with traditional exchanged diameter $(220 \mathrm{~mm})$. Calculating for the grinding time, with optimum diameter it was 2.22 $(\mathrm{min} / \mathrm{p})$ and with the traditional exchanged diameter it was $2.86(\mathrm{~min} / \mathrm{p})$. Consequently, in this case, grinding with optimum diameter can reduce the grinding cost for $13.33 \%$ and the grinding time for $22.38 \%$.

\section{Conclusion}

An experimental study on optimization of surface grinding was carried out. The cost structures for surface grinding process were analyzed. In order to determine the optimum exchanged diameter for getting the minimum grinding cost, an experimental setup was built. From the results of the experiment, the effects of exchanged diameter on the results of grinding process such as the material removal rate, the wheel life, the grinding time and the grinding cost were presented. Also, a value of optimum exchanged diameter was proposed. Grinding with this optimum diameter can save a lot of both the grinding cost and the grinding time.

\section{Acknowledgements}

The work described in this paper was supported by Thai Nguyen University of Technology for a scientific project.

\section{References}

[1] Malkin, S., and Guo, C. S. 2008. Grinding Technology:
Theory and Applications of Machining with Abrasives. Industrial Press Inc..

[2] Li, G. F., Wang, L. S., and Yang, L. B. 2002. "Multi-parameter Optimization and Control of the Cylindrical Grinding Process." Journal of Materials Processing Technology 129 (1): 232-6.

[3] Gupta, R., Shishodia, K. S., and Sekhon, G. S. 2001. "Optimization of Grinding Process Parameters Using Enumeration Method." Journal of Materials Processing Technology 112 (1): 63-7.

[4] Wen, X. M., Tay, A. A. O., and Nee, A. Y. C. 1992. "Micro-computer-based Optimization of the Surface Grinding Process." Journal of Materials Processing Technology 29 (1-3): 75-90.

[5] Krishna, A. G., and Rao, K. M. 2006. "Multi-objective Optimisation of Surface Grinding Operations Using Scatter Search Approach." The International Journal of Advanced Manufacturing Technology 29 (5): 475-80.

[6] Xiao, G., and Malkin, S. 1996. "On-line Optimization for Internal Plunge Grinding." CIRP Annals-Manufacturing Technology 45 (1): 287-92.

[7] Tönshoff, H. K., and Walter, A. 1994. "Self-tuning Fuzzy-Controller for Process Control in Internal Grinding." Fuzzy Sets and Systems 63 (3): 359-73.

[8] Pi, V. N., Khiem, V. H., and Huong, N. N. 2013. "Cost Optimization of External Cylindrical Grinding." Applied Mechanics and Materials 312: 982-9.

[9] Pi, V. N., Tung, L. A., Hung, L. X., and Long, B. T. 2016. "Cost Optimization of Surface Grinding Process." Journal of Environmental Science and Engineering A 5: 606-11.

[10] Pi, V. N., Hung, L. X., Tung, L. A., and Long, B. T. 2016. "Cost Optimization of Internal Grinding." Journal of Materials Science and Engineering B 6: 11-2.

[11] Rowe, W. B. 2013. Principles of Modern Grinding Technology. William Andrew, USA.

[12] Long, B. T., Pi, V. N., Tung, L. A., and Hung, L. X. 2013. "A Study on Building Cutting Regime Formulas for Surface Grinding." Proceedings of the 3rd National Conference on Mechanical Science and Technology. Ha Noi. 